SCIENCE OF ADVANCED MATERIALS (ISSN: 1947-2935) 7: pp. 489-495. (2015)

http://dx.doi.org/10.1166/sam.2015.1995

\title{
Polymeric Honeycombs Decorated by Nickel Nanoparticles
}

\author{
András Paszternák ${ }^{1,2}$ and David Zitoun ${ }^{1 *}$
}

${ }^{1}$ Bar Ilan University, Department of Chemistry and Bar Ilan Institute of Nanotechnology and Advanced Materials (BINA), Ramat Gan 52900, ISRAEL

2 Institute of Materials and Environmental Chemistry, Research Centre for Natural Sciences, Hungarian Academy of Sciences, 1117 Budapest, Magyar tudósok körútja 2., HUNGARY

\section{David.zitoun@biu.ac.il}

\begin{abstract}
Porous 3D metal mesostructures have a wide range of applications in different fields of micro/nanotechnology. We report on the spontaneous formation of honeycomb structures from polystyrene beads colloidal crystal and its simultaneous decoration with magnetic Ni nanoparticles. The honeycomb forms upon simple dipping of the colloidal crystal in an organic solution of an organometallic precursor. Ni nanoparticle formation is based on the gentle thermal decomposition of the organometallic precursor $\mathrm{Ni}\left(\eta^{4}-\mathrm{C}_{8} \mathrm{H}_{12}\right)_{2}$ at a temperature as low as $80^{\circ} \mathrm{C}$, compatible with the polymeric matrix. Combination of different solvents and preparation parameters are used to get an overview about the formation mechanism of $\mathrm{Ni}$ decorated honeycomb structure.
\end{abstract}

KEYWORDS: mesostructures, magnetic nanoparticles, porous materials, colloidal crystals

\section{INTRODUCTION}

Polystyrene (PS) beads are widely used as colloidal mask or templates to create uniform $2 \mathrm{D}$ or $3 \mathrm{D}$ structures with different processes, such as nanosphere lithography (NSL) ${ }^{1,2}$ electrodeposition ${ }^{3,4,5}$ or by combining these methods with gas phase synthesis. ${ }^{6}$ Colloidal lithography uses wet colloids which self-organize in macroscopic structures; the technology is inexpensive and displays high throughput and versatility. ${ }^{7}$ Honeycomb structure materials have attracted wide attention for both fundamental research and 
practical applications. ${ }^{8}$ The location and density of nanostructures is a key issue in many potential applications, such as optical antennas, sensors and bioprobes, and field emission devices. ${ }^{9}$ Using colloids, these two parameters dependon the inter-particle distance and the size of the colloids. These mesostructures can be used as photonic crystals, ${ }^{3}$ electrodes or membranes for batteries ${ }^{10,11}$ or magnetic arrays depending on the inorganic component added to the colloidal crystal. ${ }^{12,13,14}$

Highly uniform PS spheres have been decorated with noble metal nanoparticles using a soft reduction of metallic cations. ${ }^{15}$ This process has been successful with noble metal such as gold ( $\mathrm{Au})$, silver ( $\mathrm{Ag})$ or palladium $(\mathrm{Pd})$; leading to the formation of metal-PS composites. Metal loaded mesoporous structure provides the benefits of a well-designed support for the adsorbed metallic nanoparticles while preserving their individual electronic properties. ${ }^{16}$ This kind of deposition on the surface of PS beads can give nanoparticles a superior way to enhance their catalytic performance. ${ }^{17}$ PS beads multilayers have been decorated with nickel, ${ }^{18,19,20}$ in order to use the magnetic susceptibility and catalytic properties of nickel nanoparticles. The porous monometallic $\mathrm{Ni}$ or bimetallic NiFe films can exhibit high magnetic coercivity and square hysteresis compared to thin films. ${ }^{21}$ In other applications, nickel-oxide film with monodisperse open macropores - used as anode material - might facilitate the electrolyte penetration, diffusion, and migration in lithium-ion batteries. ${ }^{22}$

However, the synthesis of Ni-loaded honeycomb has not been reported and the use of organometallic Ni precursor should benefit from the large solubility of the Ni complexes in the polymers. Thermal decomposition of $\mathrm{Ni}\left(\eta^{4}-\mathrm{C}_{8} \mathrm{H}_{12}\right)_{2}$ at low temperature makes the preparation process compatible with most of the substrates, including polymers like Teflon or PDMS. ${ }^{23,24}$

In the present study, we report a one-pot route to create honeycomb structures from colloidal crystals of PS beads and to decorate these structures with Ni nanoparticles. The mechanism is based on the swelling and partial dissolution of PS beads while the outer shell of the beads forms a honeycomb loaded with Ni nanoparticles. The process has been probed by the use of different solvents and in the absence of organometallic complex.

\section{EXPERIMENTAL PROCEDURE}

\section{Polystyrene Beads Template preparation:}


Aqueous suspension of polystyrene PS beads (Thermo Scientific, Nanosphere, diameter: $800 \mathrm{~nm}$ - stabilized with polyvinylpyrrolidone (PVP)) is drop-cast on a microscopy glass, a silicon substrate (Virginia semiconductors, $<100>$, n-type, 4-6 $\Omega . \mathrm{cm}$ ) or on TEM grid (Silicon Monoxide Type-A, 300 mesh, Ted Pella). The dispersion is dried under air at room temperature under a $11 \mathrm{~W}$ white lamp to speed up the evaporation of the solvent.

\section{Honeycomb structure preparation:}

Dried PS layers on substrates are simply dipped in chloroform (Analytical grade, BioLab) for $30 \mathrm{~min}$. The substrate is then dried in air at room temperature.

\section{Ni decorated honeycomb structure preparation:}

After evaporation of the solvent, the templates created from PS beads multilayer are inserted into a nitrogen filled glove box $\left(\mathrm{H}_{2} \mathrm{O}<0.1 \mathrm{ppm}, \mathrm{O}_{2}<2 \mathrm{ppm}\right)$ and impregnated with a 0.03 mol. $\mathrm{L}^{-1}$ solution of nickel(cyclooctadiene $)_{2}\left(\mathrm{Ni}\left(\eta^{4}-\mathrm{C}_{8} \mathrm{H}_{12}\right)_{2}\right.$ or $\left.\mathrm{Ni}(\mathrm{COD})_{2}\right)$ (STREM, 98\% - stored in the glovebox at $-20{ }^{\circ} \mathrm{C}$ and used without any further purification).

Mesitylene (Acros, 97\%), THF (Acros 99.5\%), acetone (Acros 99.5\%) or methanol (Acros $99.8 \%$ ) are used as solvent for the precursor. All the solvents are dried, degassed and stored on molecular sieve $3 \mathrm{~A}$ inside the glove box.

After the impregnation, the sample is annealed for 10 minutes on a heating plate or in an oven at $80^{\circ} \mathrm{C}$ in the glove box. $\mathrm{Ni}(\mathrm{COD})_{2}$ is known to decompose into $\mathrm{Ni}(0)$ and cyclooctadiene upon heating above $80^{\circ} \mathrm{C} .^{23}$

Following the metallic treatment the samples are taken out from the glove box and are dipped in chloroform (Analytical grade, BioLab) for $30 \mathrm{~min}$ and dried. In some experiments the samples are dipped to acetone (Acros $99.5 \%$ ) inside the glove box instead of chloroform for $30 \mathrm{~min}$.

Table 1: summary of the $\mathrm{Ni}$ decorated sample preparation process with different parameters 


\begin{tabular}{|c|c|c|c|c|c|}
\hline PS beads & substrate & precursor & $\begin{array}{l}\text { solvent of } \\
\text { precursor }\end{array}$ & $\begin{array}{c}\text { heat } \\
\text { treatment }\end{array}$ & $\begin{array}{l}\text { sample } \\
\text { dipping } \\
\text { solution }\end{array}$ \\
\hline \multirow{4}{*}{$800 \mathrm{~nm}$} & glass & \multirow{4}{*}{$\mathrm{Ni}(\mathrm{COD})_{2}$} & mesitylene & \multirow{4}{*}{$\begin{array}{l}10 \text { min at } \\
80^{\circ} \mathrm{C} \\
\text { hot plate } \\
\text { or oven }\end{array}$} & \multirow{2}{*}{ chloroform } \\
\hline & silicon & & THF & & \\
\hline & \multirow{2}{*}{ TEM grid } & & acetone & & \multirow{2}{*}{ acetone } \\
\hline & & & methanol & & \\
\hline
\end{tabular}

The formation of the honeycomb structures involves the partial dissolution of the PS beads in chloroform or acetone and the nucleation and stabilization of Ni nanoparticles in the outer shell forming the composite honeycomb after percolation. Indeed, polyvinylpyrrolidone (PVP), used as a stabilizer for the PS beads (during the preparation of the Nanosphere product), is well known as a stabilizing polymer for $\mathrm{Ni}$ nanoparticles. $^{25,26}$

\section{Characterization:}

\section{Microscopy:}

The morphology of the coated sample on silicon/glass is studied using a Scanning Electron Microscope (Inspect, FEI, 3-10 kV accelerating voltage) and an Atomic Force Microscope (AFM, ICON, Bruker - in tapping mode with a silicon nitride tip (FESP)). Samples prepared on TEM grid are checked on JEM-1400, JEOL (120 kV accelerating voltage). SEM and TEM images are processed by ImageJ software and the size histograms obtained by typically measuring 200 particles, holes, walls and layers thickness and calculated the average size and standard deviation. AFM images are processed by Gwyddion software.

\section{SQUID:}

Magnetic properties are measured using a Superconducting Quantum Interference Design (SQUID) magnetometer MPMS XL7, in the range of temperature 2-300 K and of field 0$5 \mathrm{~T}$. The temperature-dependent susceptibility was measured using DC procedure. The sample was transferred under nitrogen to the SQUID chamber to prevent any oxidation. The sample was cooled to $2.0 \mathrm{~K}$ under zero magnetic field, low magnetic field (5.0 mT) was applied and data collected from $2 \mathrm{~K}$ to $300 \mathrm{~K}$ (zero-field cooled, ZFC). Field Cooled 
(FC) measurements were performed from $2 \mathrm{~K}$ to $300 \mathrm{~K}$ with an applied field during the cooling. Hysteresis loop was measured at $2 \mathrm{~K}$.

\section{RESULTS AND DISCUSSIONS}

\section{Polystyrene templates}

A self-assembled layer of polystyrene (PS) spheres stabilized with polyvinylpyrrolidone (PVP) is used as a template in the fabrication process. Monodisperse PS spheres selfassemble upon drying into an ordered crystalline structure, i.e. a colloidal crystal, in which the spheres are interconnected by Van der Waals interactions. ${ }^{27}$ Self-assembly of the PS beads is discussed in detail by Visschers et al.; ${ }^{28}$ during the drying process, the lateral capillary force between the beads drive the spheres at the suspension surface close to each other and the spheres will arrange into ordered compact layers.

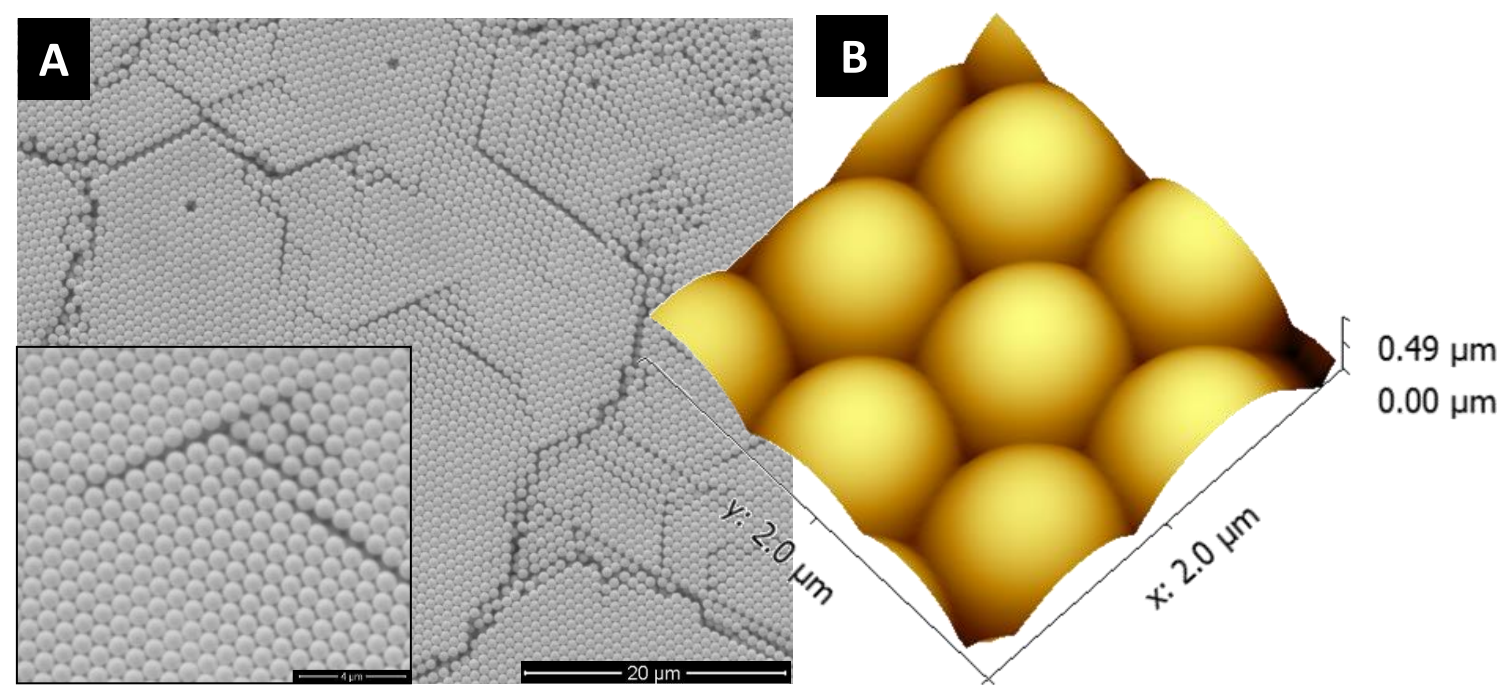

Figure 1. - PS colloidal template on Si substrate $\left(A-S E M ; D_{P S \text {-beads }}=800 \mathrm{~nm} ; \mathrm{B}-\right.$ $\left.A F M ; D_{P S \text {-beads }}=800 \mathrm{~nm}\right)$

Figure 1 displays an ordered PS layer observed by SEM (PS beads, diameter: $799 \pm 9 \mathrm{~nm}$, Fig. 1A.). One can notice the underlayer of PS beads suggesting the formation of multilayer on the surface of Si substrate by drop casting method. AFM image shows the compact ordering of the beads (Fig. 1B).

\section{PS honeycomb formation}


Following the dipping of PS beads build template to chloroform, honeycomb structure formation is observed, leading to an inverse opale structure (Fig. 2).
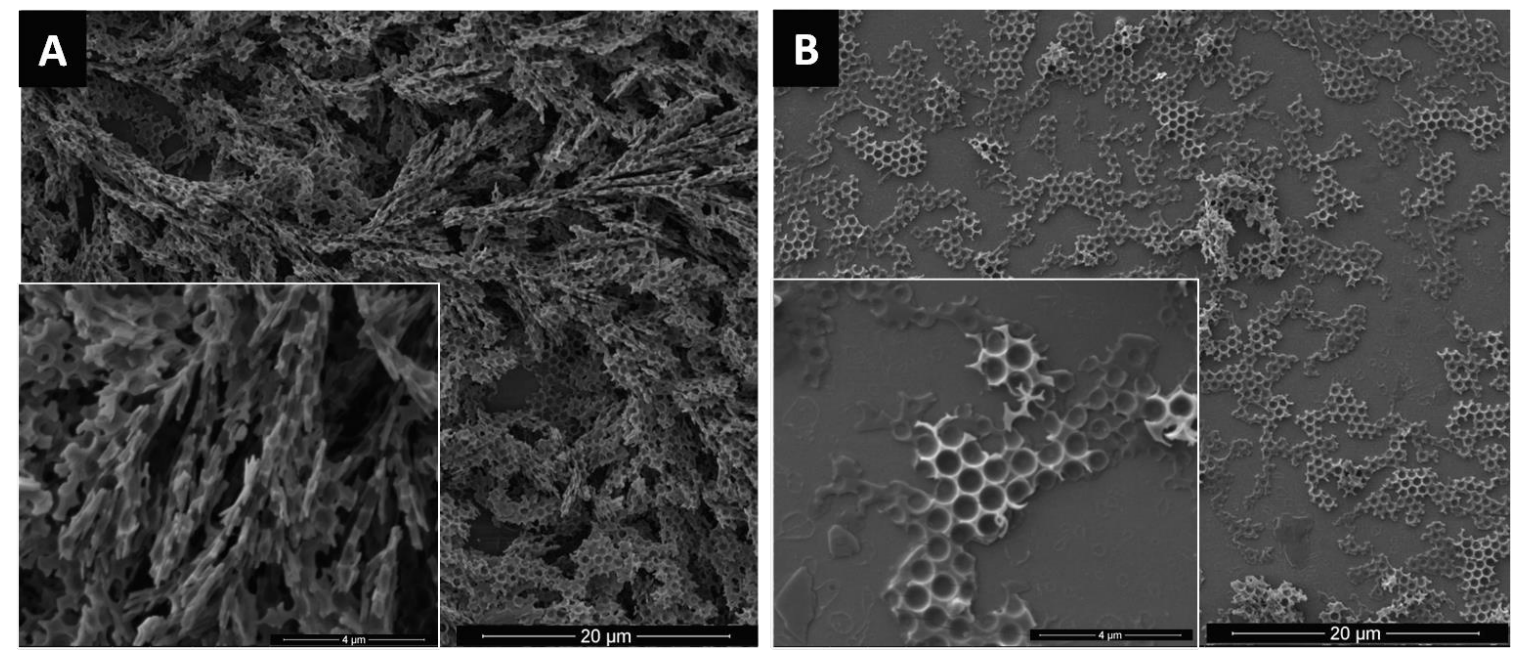

Figure 2. - SEM images of multilayered honeycomb (A) and single layered honeycomb (B) from PS beads colloidal crystal on glass after $\mathrm{CHCl}_{3}$ swelling

The density of the created structures depends on the thickness of the original colloidal crystal of PS beads, dense areas (Fig. 2A) correspond to thick film at the edge of the coating. At these locations, the layered structure is perpendicular to the substrate, as a result of an exfoliation process during the drying of the multilayers. While starting from a monolayer of PS beads, the layered honeycomb lies on the substrate (Fig. 2B). The average thickness of the layers is $200 \pm 50 \mathrm{~nm}$, the average size of the holes is $690 \pm 20$ $\mathrm{nm}$ and wall thickness $150 \pm 40 \mathrm{~nm}$.

Detailed mechanism of the honeycomb structure formation form PS layers during a different sample preparation mechanism is discussed by Bolognesi et al. ${ }^{29}$ Based on the similarity with the structures formed during chloroform dipping in our work, the hole formation mechanism may apply to our system. The authors have reported the formation of highly ordered two and three-dimensional patterns in linear PS with and without terminal polar groups. Holes result from the condensation of water micro-droplets on the evaporative cooling surface of the polymer solution. The overall phenomenon is driven by surface tension effects; self-organization of holes may be due to thermocapillary convection.

In our case, we obtain a similar result with a very high reproducibility starting from homo-polymer (PS) beads with a PVP stabilizing shell swelled in a single solvent $\left(\mathrm{CHCl}_{3}\right)$. 
Other solvents have been tested as reported in Table 2. The resulting films have been observed by SEM after the washing of the PS containing glass samples in different solvents. In the case of acetone, an unordered honeycomb structure is formed, THF disorders the colloidal crystals and PS colloidal crystals remains unaltered after ethanol or hexane treatment. Based on this series of experiments, chloroform only leads to the formation of an ordered honeycomb structure and will be used in the experiments reported below with organometallic Ni precursor.

Table 2: Morphology after swelling in different solvents observed by SEM

\begin{tabular}{|c|c|}
\hline Solvent & Observed structure \\
\hline chloroform & ordered honeycomb \\
\hline acetone & unordered honeycomb \\
\hline THF & unordered porous structure \\
\hline ethanol & Pristine PS \\
\hline hexane & Pristine PS \\
\hline
\end{tabular}

\section{Formation of PS honeycomb decorated with Ni nanoparticles}

SEM observation reveals an inverse opale structure (Fig. 3A). This honeycomb structure spontaneously forms with holes corresponding to the PS colloidal crystal used as template. The average size of the holes stands as $710 \pm 50 \mathrm{~nm}$. Lattice constant of the honeycomb is therefore very close to the one observed in the colloidal crystal and similar to the process without $\mathrm{Ni}$ organometallic precursor. EDAX measurements confirm the presence of $\mathrm{Ni}$ in the created honeycomb structures (Fig. 3B). Detailed XRD characterization of $\mathrm{Ni}$ nanoparticles formed during the thermal decomposition of $\mathrm{Ni}$ precursor at low temperature is presented in our previous paper. ${ }^{30}$ 

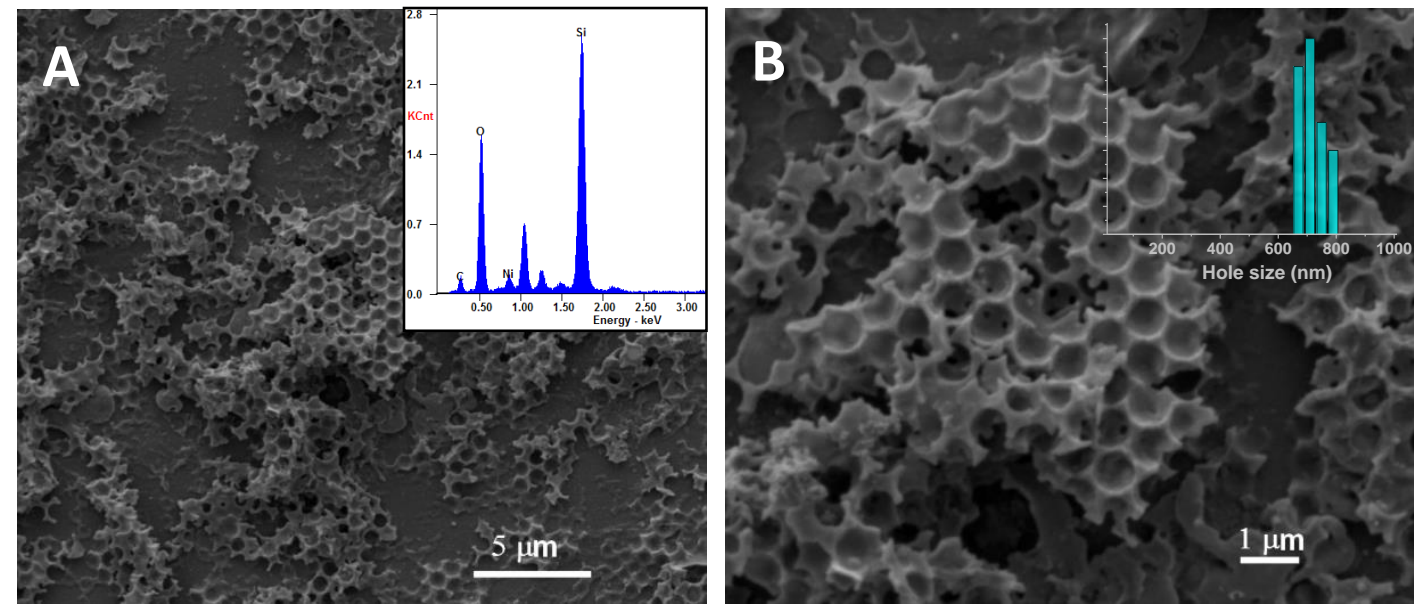

Figure 3. - SEM image of the honeycomb from drop casting a THF solution of Ni precursor $\left(80^{\circ} \mathrm{C}, \mathrm{CHCl}_{3}\right.$ treatment) with $\mathrm{EDAX}$ result (A) and size histogram of the hole size $(B)$

As displayed on Fig. 3, the Ni nanoparticles do not show up in the HRSEM study and on can observe only the honeycomb. Therefore, TEM is used to check the presence of $\mathrm{Ni}$ Uniform $\mathrm{Ni}$ nanoparticles, $9.3 \pm 1.2 \mathrm{~nm}$ in diameter, are observed from the used chloroform dipping solution, inferring that the honeycomb is loaded with the very same nanoparticles (Fig. 4). The particles adopt several morphologies with a tendency to form faceted nanoparticles (square or triangular cross-section) as already described in a previous report. $^{24}$
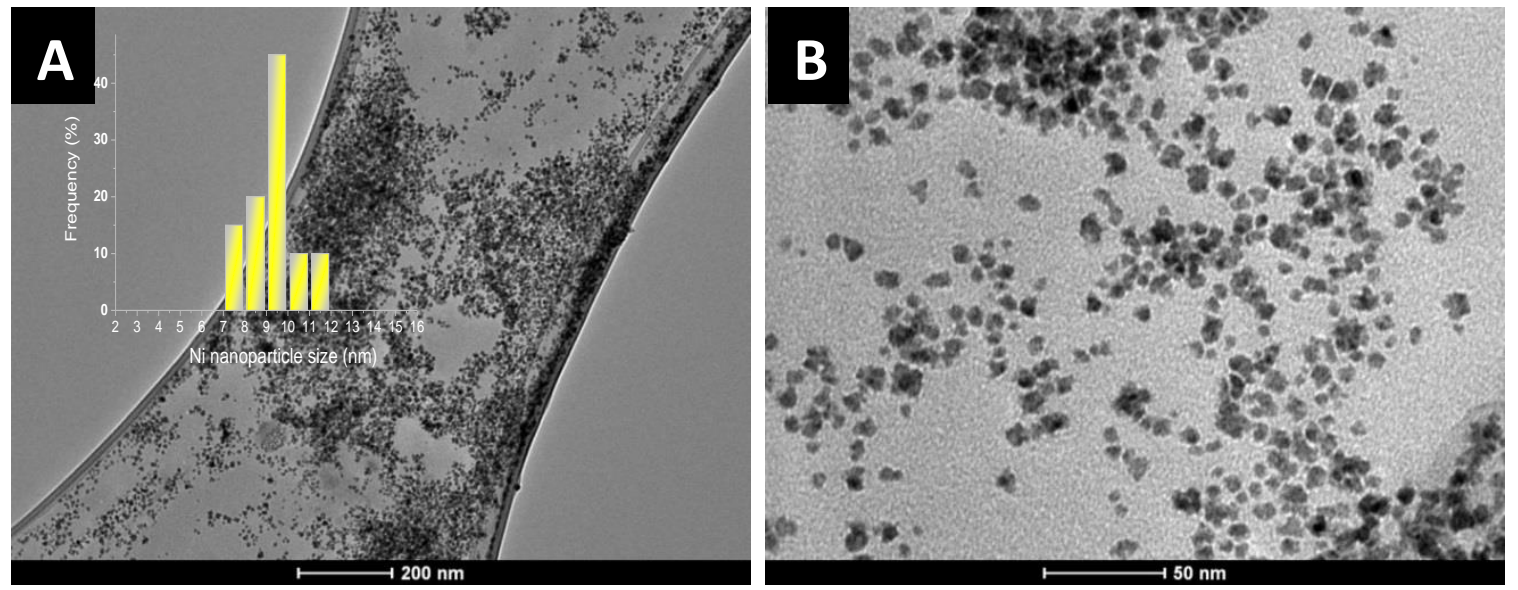

Figure 4. TEM of Ni nanoparticles with different magnifications and their size histogram (A and B) 
To understand the processes occurring during the sample preparation, the procedure is repeated directly on a silicon monoxide coated TEM grid. PS beads are assembled by drop casting and evaporation on the surface of the grid, Ni precursor is then thermally decomposed, following the same procedure described previously on glass and Si wafer. From TEM imaging (Fig. 5), the fingerprint of the PS bead is clearly visible and nickel nanoparticles decorate the wall. The average size of these particles is $8.3 \pm 1.3 \mathrm{~nm}$, matching the size observed on glass substrate. The density of particles increases from the center to the edges with an average thickness of $150 \mathrm{~nm}$ matcxhing the wall thickness observed by SEM on Fig. 3. The Selected Area Electron Diffraction (SAED) shows diffuse rings with the most intense corresponding to the (111) lattice fringes of facecentered cubic (FCC) phase with lattice parameters of bulk Ni (Fm-3 m, a = $3.52 \AA)$ (JCPDS-04-0850).
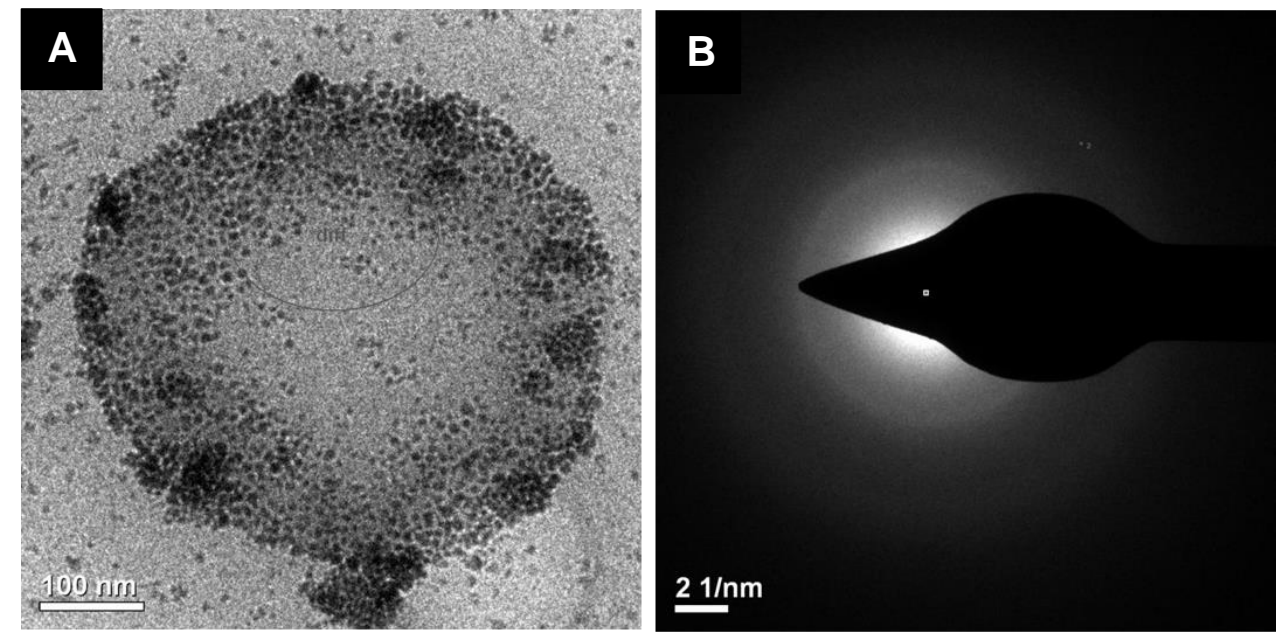

Figure 5. - TEM study of the Ni nanoparticles resulting from the process achieved directly on a TEM grid (A) and the corresponding Selected Area Electron Diffraction (SAED) (B)

The honeycomb structure exhibits a rough surface as clearly visible on AFM images (Fig. 6) on the sample after the chloroform dipping. The roughness can be attributed to the PS swelling process and also to presence of Ni nanoparticles in/on the walls of the pores. 


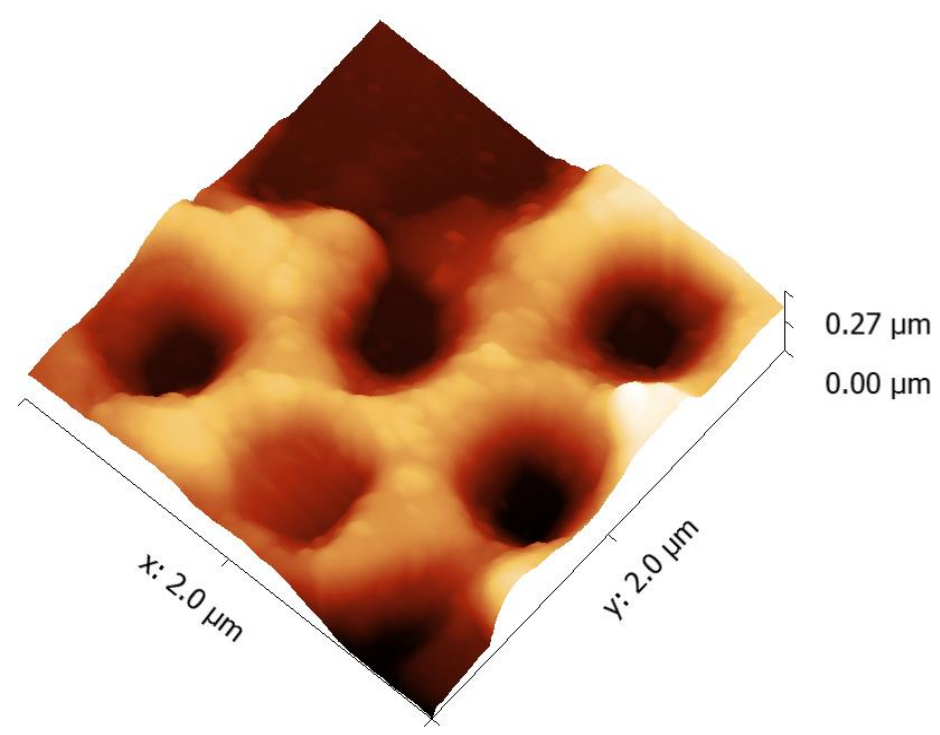

Figure 6: AFM image of the honeycomb/Ni composite showing high roughness

THF has also been replaced by other solvents (see Table 1. in experimental section). Results obtained with methanol are presented in Fig. 7. The average hole size of the structure is $850 \pm 70 \mathrm{~nm}, 17 \%$ larger than in the case of THF. The honeycomb is disordered; the average thickness of the walls $(110 \pm 20 \mathrm{~nm})$ is similar as the samples obtained from THF $(120 \pm 20 \mathrm{~nm})$.

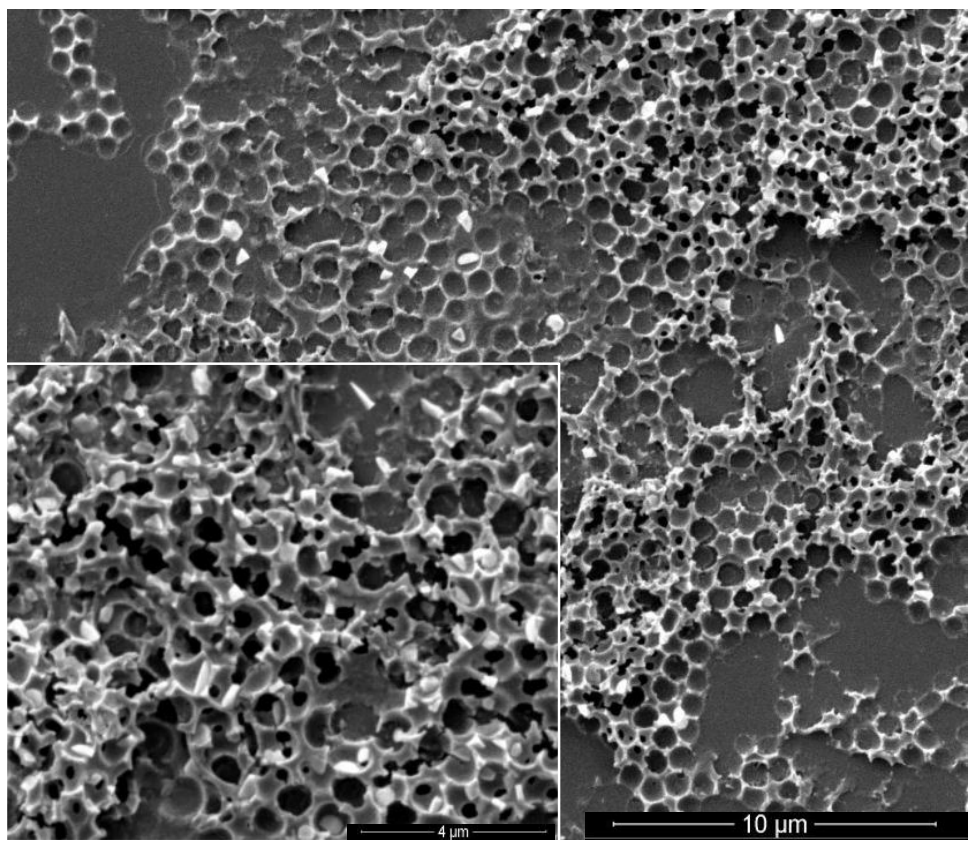

Figure 7. - SEM images of Ni/PS honeycombs obtained from $\mathrm{Ni}(\mathrm{COD})_{2}$ dissolved in methanol followed by swelling/dissolution in $\mathrm{CHCl}_{3}$. 
Different solvents are tested also for second step (sample dipping solution column in Table 1.), originally planned as polymer beads dissolving process. All samples display the inverse opale morphology (Fig. 8) with a larger disorder than in the case of THF (solvent for $\mathrm{Ni}$ precursor)/ $\mathrm{CHCl}_{3}$ (dipping solvent) process (Figure 3).

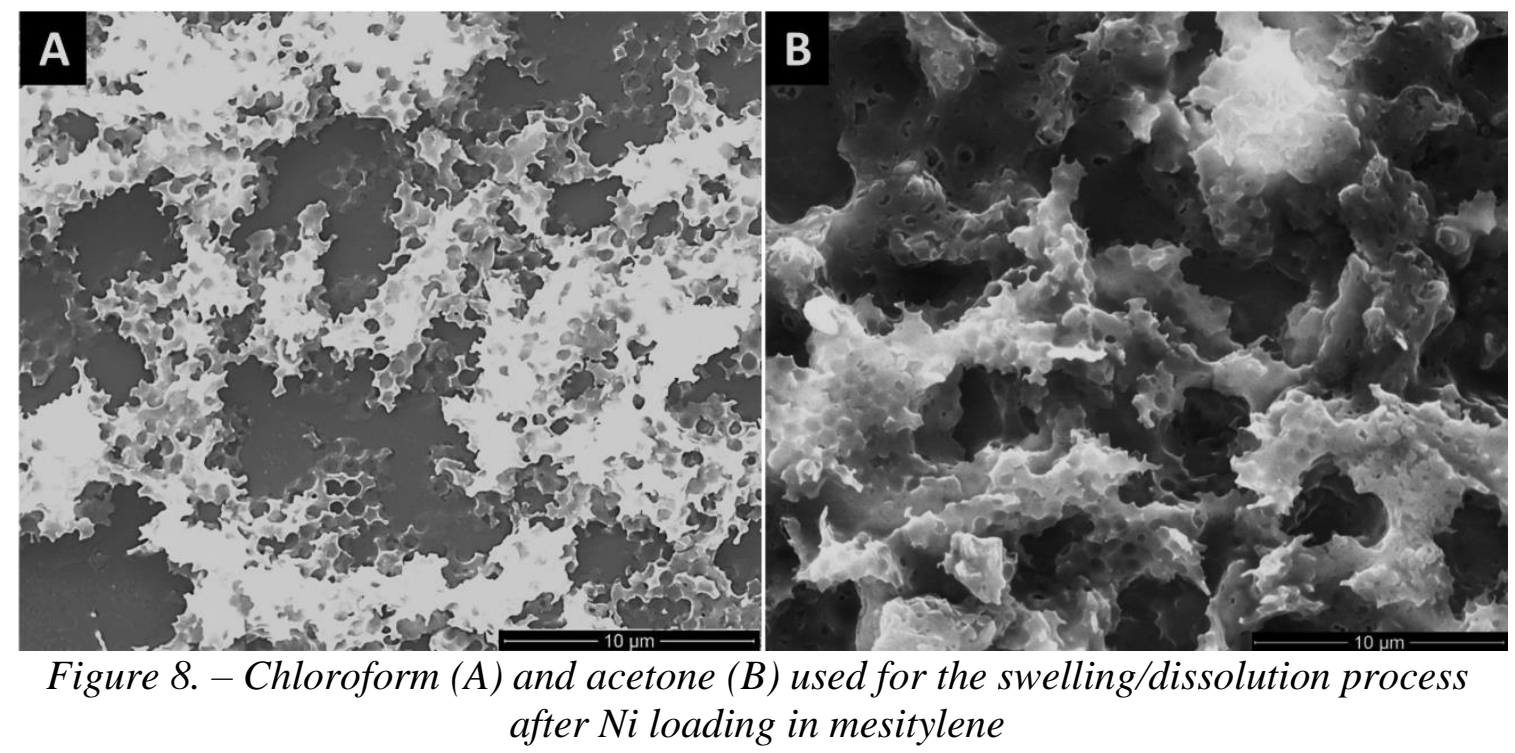

PS templates treated with metal precursor from mesitylene and dipped in chloroform (Fig. 8A) and acetone (Fig. 8B) are presented. On both samples the Ni decorated honeycomb structures are created with average hole size of $680 \pm 80 \mathrm{~nm}(\mathrm{~A})$ and $650 \pm$ $80 \mathrm{~nm}$ (B). No significant differences are found between the formed structures, although the physical parameters of the two solvents significantly differ with surface tension of $25.20 \mathrm{mN} / \mathrm{m}$ and $27.50 \mathrm{mN} / \mathrm{m}$ at $20^{\circ} \mathrm{C}$; polarity index of $\mathrm{P}^{\prime}=4.1$ and 5.1 , for chloroform and acetone respectively. This result points out the relative versatility of the phenomenon where the solvent needs only to dissolve the PS to lead to honeycomb, regardless of the evaporation speed.

\section{Magnetic characterization}

Magnetic measurements on the Ni decorated samples have been performed in a SQUID magnetometer. Two sets of experiments are needed to evaluate the quality of the film. First, low temperature hysteresis are measured on the sample at $2 \mathrm{~K}$ (Fig. 9A). The magnetic measurements are collected on $5 * 5 \mathrm{~mm}^{2}$ samples with a magnetization in the $10^{-3} \mu_{\mathrm{B}}$ range and no coercitive field. The magnetic moment saturates at $2 \mathrm{~T}$ with different magnetic moment for each solvent respectively, one cannot calculate the normalized 
magnetic moment due to the uncertainty on the Ni loading. We have then measured the temperature dependence of the magnetization following a zero-field-cooled/field-cooled (ZFC/FC) measurement from $2 \mathrm{~K}$ to $300 \mathrm{~K}$ with an applied external field $\mu_{0} \mathrm{H}=5.0 \mathrm{mT}$ (Fig. 9B). The ZFC/FC displays a hysteresis below a temperature of $200 \mathrm{~K}$. This behavior could be assigned to the presence of aggregated superparamagnetic nanoparticles as observed from TEM. Indeed, the blocking temperature of isolated $9 \mathrm{~nm} \mathrm{Ni}$ nanoparticles is calculated as $T_{B}=53 \mathrm{~K}$ following the equation $T_{B}=K V / 25 k_{B}$, where $K$ is the magnetocrystalline anisotropy $\left(\mathrm{K}=4.810^{4} \mathrm{~J} / \mathrm{m}^{3}\right.$ for bulk Ni, $\mathrm{V}$ is the particle volume and $\mathrm{k}_{\mathrm{B}}$ the Boltzmann constant). ${ }^{31}$ Since the previous equation is valid only for noninteracting monodisperse magnetic nanoparticles, the higher blocking observed can be explained by magnetic dipolar interactions within the aggregates.
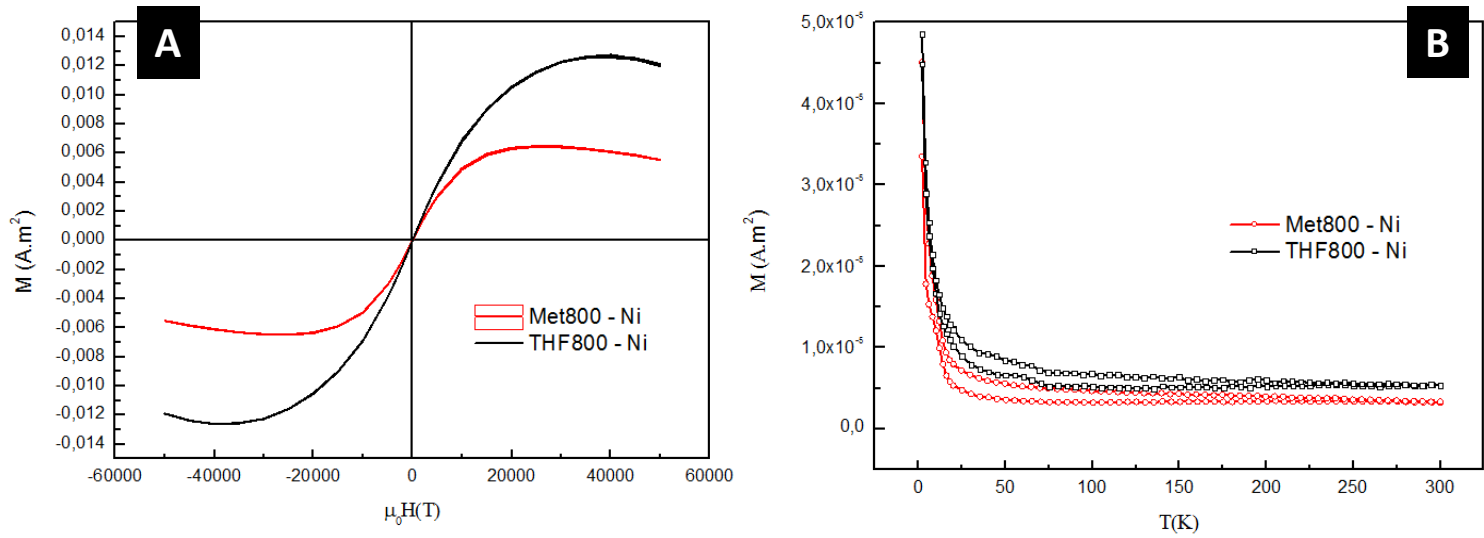

Figure 9. - Magnetic characterization of Ni decorated PS honeycombs from methanol or THF: hysteresis curves at $2 \mathrm{~K}(\mathrm{~A})$ and $\mathrm{ZFC} / \mathrm{FC}$ curves at $\mu_{0} H=5.0 \mathrm{mT}(\mathrm{B})$

\section{CONCLUSION}

The swelling of colloidal crystals of PS beads in an organometallic Ni precursor results in the formation of honeycomb structures with a quantitative yield at low temperature. Magnetic $\mathrm{Ni}$ nanoparticles form in the wall of the honeycomb and display a superparamagnetic behavior. In a controlled experiment without organometallic $\mathrm{Ni}$ precursor, the swelling of the colloidal crystal with a single solvent successfully yields honeycomb structures. The honeycomb structures display short range ordering, with a strong dependence on the swelling solvent, the most ordered structure being obtained with chloroform. The formation of the honeycomb involves the partial dissolution of the 
PS beads and the nucleation/stabilization of Ni nanoparticles in the outer shell (PVP rich) forming the composite honeycomb after percolation.

\section{ACKNOWLEDGMENT.}

The authors wish to thank Bar Ilan Institute of Nanotechnology and Advanced Materials (BINA) staff for SEM, TEM and SQUID measurements.

\section{REFERENCES}

1. S. L. Cheng, S.W. Li, C. H. Li, Y. C. Chang, C. K. Huang, and H. Chen, Thin Solid Films 494, 307 (2006)

2. J. Yu, Ch. Geng, L. Zheng, Z. Ma, T. Tan, X. Wang, Q. Yan, and D. Shen, Langmuir 28, 12681 (2012)

3. Y. Li, B. Ma, J. Zhao, W. Xina, and X. Wang, J. of Alloys and Compounds 509, 290 (2011)

4. M.-S.Wu, and K.-Ch. Huang, Inter. J. Hydrogen En. 36, 13407 (2011)

5. W. Xina, L. Yang, J. Zhao, and Y. Li, Appl. Surf. Sc. 258, 7059 (2012)

6. X. Chen, X. Wei, and K. Jiang, Microelectronic Engineering 86, 871 (2009)

7. C. Acikgoz, M. A. Hempenius, J. Huskens, and G. J. Vancso, European Polymer Journal 47, 2033 (2011)

8. L. Heng, B. Wang, M. Li, Y. Zhang, and L. Jiang, Materials 6, 460 (2013)

9. J.-H. Lee, Y.-W. Chung, M.-H. Hon, and I.-C. Leu, Journal of Alloys and Compounds 509, 6528 (2011)

10. Y. F. Yuan, X. H. Xia, J. B. Wu, J. L. Yang, Y. B. Chen, and S. Y. Guo, Electrochem. Comm. 12, 890 (2010)

11. F.-S. Ke, L. Huang, H.-H. Jiang, H.-B. Wei, F.-Z. Yang, and S.-G. Sun, Electrochem. Comm. 9, 228 (2007)

12. A. A. Zhukov, M. A. Ghanem, A. V. Goncharov, P. A.J. de Groot, I. S. El-Hallag, P.

N. Bartlett, R. Boardman, and H. J. Fangohr, Magn. Magn. Mater. 272, 1621 (2004)

13. Ch.-Y. Kuo, K.-H. Huang, S.-Y. Lu, J. Taiwan Institute of Chemical Engineers 42, 186 (2011)

14. T. S. Eagleton, and P. C. Searson, Chem. Mater. 16, 5027 (2004)

15. J. L. Ou, C. P. Chang, Y. Sung, K. L. Ou, C. C. Tseng,H.W. Ling, and M. D. Ger, Colloids and Surfaces A: Physicochem. Eng. Aspects 305, 36 (2007)

16. C.-P. Chang, Ch.-Ch. Tseng, J.-L. Ou, W.-H. Hwu, and M. D. Ger, Colloid. Polym.

Sc. 288, 395, (2010)

17. T. Tamai, M. Watanabe, T. Teramura, N. Nishioka, and K. Matsukawa, Macromol.

Symp. 282, 199 (2009) 
18. J. Jiang, H. Lu, L. Zhang, and N. Xu, Surface \& Coatings Technology 201, 7174 (2007)

19. S. Wang, W.-L. Yang, G.-B. Yu, S.-H. Xie, M.-H. Qiao, and K.-N. Fan, Chinese Journal of Chemistry 26, 1191 (2008)

20. M. Chen, J. Zhou, L. Xie, G. Gu, and L. J. Wu, J. Phys. Chem. C 111, 11829 (2007)

21. R. Han, W. Pan, S. Shi, H. Wu, and S. Liu, Materials Letters 61, 5014 (2007)

22. M.-S. Wu, and Y.-P. Li, Electrochim. Acta 56, 2068 (2011)

23. M. Shviro, and D. Zitoun, Nanoscale 4, 762 (2012)

24. M. Shviro, and D. Zitoun, RSC Adv. 3, 1380 (2013)

25. D. De Caro, and J. Bradley, Langmuir 13, 3067 (1997)

26. T. Ould-Ely, C. Amiens, B. Chaudret, E. Snoeck, M. Verelst, M. Respaud, and J.

Broto, Chem. Mater. 11, 526 (1999)

27. H. Zhang, R.-G. Duan, F. Li, Q. Tang, and W.-Ch. Li, Materials and Design 28, 1045 (2007)

28. M. Visschers, J. Laven, and R. van der Linde, Progress in Organic Coatings 31, 311 (1997)

29. A. Bolognesi, C. Mercogliano, S. Yunus, M. Civardi, and . Comoretto, and A.

Turturro, Langmuir 21, 3480 (2005)

30. M. Shviro, A. Paszternák, A. Chelly, and D. Zitoun, J. Nanopart Res 15, 1823 (2013)

31. D. L. Leslie-Peckely, R. D. Rieke Chem. Mater. 8, 1770 (1996) 